\title{
STRANGULATION ASPHYXIA
}

\section{Vasiliy Yekhalov ${ }^{1}$ \\ Natalia Khobotova ${ }^{2}$}

DOI: https://doi.org/10.30525/978-9934-588-15-0-66

\begin{abstract}
Strangulation asphyxia (SA) is one of the types of acute airway obstruction that occurs during direct compression of the trachea, blood vessels and nerve trunks of the neck. Characteristic of this type of asphyxia are rapidly growing hypoxemia and hypercapnia, deep disturbances of
\end{abstract} cerebral circulation by hemorrhagic type, hypoxic/anoxic encephalopathy. There are three main categories compression of the neck: hanging, ligature strangulation, suffocation by hands. The difference between these three concepts is explained by the cause of the external compression of the neckeither a tightening strip tensed by the gravitational weight of the body, or by part of the body; tightening strip provided by a force other than body weight (ligature strangulation); or external pressure by the arms, forearms, or other limbs (suffocation by the hands). "Hanging in falling from height (with a jerk)" is not a typical form of strangulation asphyxia and is not a suffocation subtype. The main clinical signs of strangulation in dependence to its duration: in the overwhelming majority of victims who were brought to the hospital alive, the level of consciousness by the Glasgow scale was defined as $<8$. In most of the surviving patients this indicator was more than 3 points. Obstruction of venous outflow from the brain leads to congestive hypoxia and loss of consciousness in just 15 seconds. Complications of strangulation asphyxia: post-hypoxic/post-anoxic encephalopathy; cases of temporary vision loss are known, in a number of cases - "tympanic membrane syndrome"; chondroperichondritis; damage to the cervical spinal cord is accompanied by appropriate neurological symptoms in the form of

\footnotetext{
${ }^{1}$ Candidate of Medical Sciences, Associate Professor of the Department of Anesthesiologi, Intensive Care and Emergency States of FPE

SE "Dnipropetrovsk Medical Academy of HM of Ukraine", Ukraine

${ }^{2}$ Candidate of Medical Sciences,

Assistant Professor of the Department of ENT Diseases

SE "Dnipropetrovsk Medical Academy of HM of Ukraine", Ukraine

(C) Vasiliy Yekhalov, Natalia Khobotova
} 
tetraplegia or tetraparesis, tetraanesthesia, respiratory disorders (in damage to the fourth cervical segment); laryngeal deformity, dysphonia, dysphagia, wheezing breathing, hoarseness can be observed. Prophylaxis: proper care of children, persons with disabilities and mental disorders (including the elimination of the technical possibility of hanging); compliance with safety precautions when working with rotating mechanisms; riding in cabriolets, motorcycles, mopeds, etc; prevention and treatment of alcoholism, drug addiction (drug dependency treatment); prevention and treatment of suicidal intentions and sexual perversions (psychological and psychiatric care).

\section{Introduction}

Strangulation asphyxia (SA) is one of the types of acute airway obstruction that occurs during direct compression of the trachea, blood vessels and nerve trunks of the neck. Characteristic of this type of asphyxia are rapidly growing hypoxemia and hypercapnia, deep disturbances of cerebral circulation by hemorrhagic type, hypoxic/anoxic encephalopathy.

Scientific and practical novelty: In the available specialized literature on the subject of "strangulation asphyxia" questions of post-mortem forensic medical examination prevail overwhelmingly, while questions of pathogenesis, diagnosis and medical care rendered to such victims are given little attention. Based on the domestic and foreign scientific research, personal theoretical and clinical experience, we developed the algorithm for diagnostics and medical assistance at the stages of the victim's route with various types of strangulation asphyxiation from the level of civilian rescuers to the stage of specialized assistance.

Relevance of the topic and statistical data: In the developed countries, hanging constitutes $5 \%$ of all injuries, and taking into account other types of strangulation asphyxia in some countries, makes up to $10 \%$ of all injuries (up to $2.5 \%$ of all deaths as a result of injury).

By the number of attempted suicides per 100.000 of the world's population, Guyana ranks first (44.2), DPRK ranks second (38.5), South Korea (28.9) ranks third, Sri Lanka is fourth (28.8), Lithuania is fifth (28.2), Russia - 12th place (19.5), Ukraine - 24th (16.8) among 172 countries of the world. In Australia the figure is 11 per 100.000 citizens, and in the UK it is 10.9.

The most common reason for attempted suicide was the effect of alcohol (31\%), followed by a domestic quarrel (18\%), chronic illness $(9 \%)$ 
and failure in exams (7\%). No reason was identified in $31 \%$ of patients. Suicide rates are particularly high among the most vulnerable groups that are discriminated: refugees and migrants, lesbians, homosexuals, bisexuals, transsexuals and intersexuals, mental patients, as well as prisoners.

WHO presumes that the number of attempted suicides among the adult population is more than twenty times exceeds that of exercised. Men commit suicide 3-4 times more often than women.

To date, only a few countries have included prevention of suicide among their health priorities, and only 28 countries have reported about having a national suicide prevention strategy. The Ukrainian government has implemented several anti-suicide programs, but they are not effective enough. In 2010, the Verkhovna Rada of Ukraine initiated a draft law "On the concept of state policy to prevent alcohol abuse", the authors of which motivated it by saying that at least half of the Ukrainian murderers were drunk at the time of the crime commitment as well as about $40 \%$ of selfmurderers.

In the structure of attempted suicides, hanging makes up $84.3 \%$ in Russia, in the UK it accounts for $58 \%$ and $43 \%$ of suicides among men and women, in Australia - 54.4\%, in Ukraine, Lithuania, Belarus, Kazakhstan and Turkmenistan $-54.5 \%$, in India $-28 \%$ (40\% of attempted suicides with pesticides using), in the United States - 23\% (46\% of suicides - gunshot wounds due to the availability of small arms).

Only a small proportion (about 10\%) of cases of self-hanging occurs in a controlled environment of hospitals, prisons and police stations; the rest occur in society. Among suicidal attempts in psychiatric wards, strangulation asphyxia makes up $75 \%$.

In recent years, researchers are increasingly discussing the problem of possible underestimation of the number of attempted self-hanging by official statistics due to their unreasonable classification as the so-called "damage with indefinite intentions" (heading Y10-Y34 of the International Classification of Diseases and Causes of Death).

Children who have recently learned to stand and walk, adolescents, as well as people aged 30 to 40 years old are considered to be at risk of injury and death as a result of hanging. Criminal hanging and death by hanging which is legally accepted in some countries now makes up an insignificant part of deaths as a result of this type of injury. 
Women more often become the victims of manual strangulation than men. However, in the structure of attempted killing, this type of strangulation asphyxia is only $8.6 \%$. Non-lethal manual strangulation is probably underestimated, especially on the part of intimate partner violence. The prevalence of the phenomenon of sexual suicide has not been studied reliably. Estimates of scientists on this subject are very approximate. American sociologists assume that every year in the United States there can be from 200 to 1000 deaths against the background of asphyxiophilia.

Lethality after attempted suicide by hanging is about $70 \%$; the majority $(80-90 \%)$ of those who check into a hospital with heart function survive.

\section{Classification of strangulation asphyxia}

1. Typical hanging (complete) - compression of the neck organs with a loop under the force of gravity of the body, when the legs do not touch the support:

slow,

with a jerk.

2. Atypical hanging (incomplete) - compression of the neck organs with a loop under the force of gravity of the body in a position on the knees, sitting, lying, with fixing of the head and neck in holes of smaller diameter or above the support (postural asphyxia).

3. Mechanical strangulation - compression of the neck by the hands, by the stranglehold.

Strangulation asphyxia can be fatal or non-fatal.

4. Incomplete hanging is a pathological condition when a patient is delivered to a medical facility alive.

5. Postural asphyxia is a type of incomplete hanging that occurs as a result of compression of the neck organs when the head is fixed above the support.

Suffocation is defined as asphyxia by blocking the blood vessels and / or the airways of the neck as a result of external pressure on the neck. A number of foreign authors believe that the term "suffocation" should not be used as a synonym for "hanging".

There are three main categories compression of the neck:

hanging;

ligature strangulation;

suffocation by hands. 
The difference between these three concepts is explained by the cause of the external compression of the neck - either a tightening strip tensed by the gravitational weight of the body, or by part of the body; tightening strip provided by a force other than body weight (ligature strangulation); or external pressure by the arms, forearms, or other limbs (suffocation by the hands).

"Hanging in falling from height (with a jerk)" is not a typical form of strangulation asphyxia and is not a suffocation subtype. Death in these cases is associated with the dislocation of the upper cervical vertebrae, and not with asphyxia. In fact, spinal cord injuries are practically absent in typical hanging or suffocation, they occur most often in hanging with a jerk. When the term "hanging" is properly used, excluding falling from height, there are only three possible death mechanisms:

- overlapping of blood vessels of the neck;

- compression of the airways;

- vagal inhibition during irritation of the baroreceptors in the carotid sinus and the body of the carotid artery.

The most frequently used ligatures for attempted suicides (rope, belts, clothes items, sari, bed-clothes) and ligature points (beams, railings, hooks, door handles and trees). If strangulation is of erotic character, the material of a loop is usually soft, atraumatic. Suffocation with an electric wire is usually the result of an accident or work injury (very rarely). Other objects, such as a chair back or crutch can be used for strangulation.

An example of hanging with the help of various tools is the use of the tool "Uprightjerker". This tool was used for carrying out executions in the USA in the XIX and early XX centuries.

\section{Risk factors for strangulation asphyxia:}

a) mental illness and psychotic reactions;

b) criminal offence;

c) improper supervision over infants, young children, incapacitated persons;

d) alcohol or drug intoxication;

e) sexual perversions (pseudo-hanging, asphyxiophilia, scarfing);

f) accidents at work, in transport and in everyday life - when the ends of scarves, kerchiefs, neckties, ribbons, etc. get into the moving parts of the mechanisms (quite rarely). 


\section{Stages of the dying process}

The process of dying from strangulation asphyxia is divided into 4 stages (each of them lasts several seconds or minutes).

- Stage I is characterized by preservation of consciousness, deep and frequent breathing with the participation of all auxiliary muscles, progressive cyanosis of the skin, tachycardia, increased arterial and venous pressure, consciousness is preserved.

- Stage II - consciousness is lost, convulsions develop, respiration becomes infrequent, motor excitation is observed, muscle tone is increased, possible convulsions, tongue bitting, hemorrhages in the sclera and conjunctiva of the eyes are possible. Puffy face, of purple-cyanotic color, swollen neck veins, nose bleeding, discharge of pink foam from the mouth, involuntary urination and defecation, ejaculation, pushing of cervical plug. On the ECG - changes characteristic of acute hypoxia.

- Stage III - respiratory arrest lasts from a few seconds to 1-2 minutes (terminal pause).

- Stage IV - agonal breathing changes into respiratory arrest and clinical death occurs.

\section{Mechanisms of damage in strangulation asphyxia:}

- Respiratory anoxia itself (which is especially pronounced in the anterior and anterior-lateral position of the loop), in which there is a complete overlap of the airways.

- Compression of the arteries supplying the brain, acute brain ischemia.

- Constriction of the neurovascular bundle, carotid arteries and superior venae cavae. In this case, death occurs as a result of overflow of blood vessels of the brain, as blood continues to flow through the vertebral arteries. A sharp and significant increase in intracranial pressure (swelling of the brain, intracranial hemorrhage). Swelling and compression of the brain tissue develop.

- Short-term spasm of cerebral vessels and later - vasodilatation with deep disorder of cerebral circulation or diffuse cerebral hemorrhages.

- Reflex effects in irritation of the carotid sinuses (vagal collapse), including when the tension of the carotid arteries is caused by the weight of the hanging body. Especially often this is observed if the loop is located above the larynx. 
- Mechanical irritation of the neck extero- and interoreceptors. Constriction of the recurrent nerve causes a series of pathological impulses, complicated by the reflex arrest of blood circulation, especially in concomitant cardiovascular pathology.

- Injuries to the spinal cord, medulla oblongata, especially in hanging with a jerk. Spinal cord injuries are rarely seen in pediatric asphyxia.

- Injuries of the cervical spine, trachea, cartilages of the larynx, thyroid cartilage, hyoid bone, tears and breakings of the intima of the cervical arterial vessels (Amussat's sign), hemorrhages in the skin, mucous membranes, internal organs. Traumatic changes of the cervical spine and the base of the skull in this case are represented by the so-called palatal fractures or "hangman's fracture." The specificity of these fractures is determined by the location of the loop knot and the direction of the effort. When the knot is located under the chin, avulsion of the arc of the second cervical vertebra is observed ("English hanging"). When the knot is located behind the ear ("Roman hanging"), fracture of the occipital condyle is observed. These injuries are accompanied by injuries of the brain stem and superior cervical spinal cord, incompatible with life. Death in hanging with a jerk (rupture of the spinal cord) occurs almost instantly, within fractions of a second (the speed of the impulse moving along the nerve guides is about $50 \mathrm{~m} / \mathrm{sec}$.). In England, in 1868, for the execution, the "long fall" method as "more humane" was adopted by the law, which is not entirely true, since the brain still remains alive for 2.7 to 10 seconds.

- In SA, the greatest changes are observed in phylogenetically younger parts of the brain and in those parts whose blood supply is less abundant: in the cortex, cornu ammonis, and cerebellum. Oblongated marrow and spinal cord suffer to a lesser extent. Disturbance in the oxygen supply of ganglion cells causes severe dystrophic changes in certain areas of the brain. The jugular veins are the first compressed structures (effort $2 \mathrm{~kg}$ ), followed by compression of the carotid arteries $(5 \mathrm{~kg})$, which cause cerebral edema and its hypoxic damage. Compression of the airways requires more strength $(15 \mathrm{~kg})$, which can lead to a severe hypoxia and death. Neurological outcomes in hanging range from permanent hypoxic brain damage to full recovery. Unusual symptoms include carotid and vertebral artery rupture, post-hypoxic/post-anoxic encephalopathy syndrome, hyperthermia, retrograde amnesia, and Korsakoff psychosis. 
- Two mechanisms have been proposed as causes of pulmonary edema. Neurogenic pulmonary edema occurs as a result of a centrally-mediated massive sympathetic discharge after anoxic brain damage. Pulmonary complications are often responsible for the delayed mortality in survivors of incomplete hanging and strangulation.

- Amnesia is caused by compression of the carotid arteries, causing ischemic damage to the hippocampus. This can be caused by cerebral edema as a result of venous obstruction. Most of these patients thought they were hospitalized for another medical reason, such as fever and cold (false memories). The fact that they did not remember how they had hung made it more difficult to offer them psychiatric counseling.

-Even the application of arterial tourniquet can cause ischemic damage to the muscles with the development of hypermyoglobinemia and systemic disorders after removal of the tourniquet. The degree of myoglobinemia correlates with the length of tourniquet application. In SA, rhabdomyolysis occurs as a result of the mechanical crushing of muscular tissue in the neck area, is regarded as a "crash syndrome" of varying severity, aggravated by involuntary and jerky movements, which are often observed in typical hanging.

\section{The main clinical signs of strangulation in dependence to its duration:}

- In the overwhelming majority of victims who were brought to the hospital alive, the level of consciousness by the Glasgow scale was defined as $<8$. In most of the surviving patients this indicator was more than 3 points. Obstruction of venous outflow from the brain leads to congestive hypoxia and loss of consciousness in just 15 seconds. The resulting reduction in the muscle tone makes it possible to strengthen external force and leads to complete arterial occlusion, brain damage and death.

- According to the data of Mikhailichenko Yu.I. (1979), in hanging anisocoria is sometimes observed, and a dilated pupil is more often defined on the side of the greatest compression of the neck by the loop. Less commonly, it is observed on the opposite side, as a result of pressure on the superior cervical sympathetic ganglion and postganglionic fibers emerging from it.

- During short-term compression of the neck, cardiac activity is not sharply disturbed: after a period of bradycardia and then tachycardia, the pulse of satisfactory filling and tension is quickly restored. 
- During strangulation with a duration of 3-4 minutes, bradycardia is observed, with the restoration of respiration an increase in the pulse occurs. Blood pressure remains low for several hours.

- During strangulation with a duration of 5-6 minutes, the pulse is weak, filiform, persistent hypotension.

- With a period of more than 6-7 minutes, the pulse is often not detected, if the activity of the heart can be restored, the diastolic pressure is not detected, the pulse remains extremely unstable. Marked sinus arrhythmia, electrical alteration of myocardial excitability, ventricular premature beats, paroxysmal tachycardia, shift of the electrical axis of the heart to the right are noted. The cause of death is also sudden cardiac arrest as a result of acute heart failure, which develops shortly after pulling out of the loop.

- Strangulation lasting more than 7-8 minutes is absolutely terminal.

- Persistent febrile reaction:

- after compression of the neck for 2-3 minutes, the average increase in $\mathrm{t}^{\circ}$ is about $37.2{ }^{\circ} \mathrm{C}$,

- after 9-minutes' strangulation $-39.6{ }^{\circ} \mathrm{C}$ (an extremely dangerous sign, a harbinger of death).

- Hemodynamic indicators:

1. Arterial hypertension $(200 \mathrm{mmHg}$ and higher $)+$ tachycardia (160 - 180 beats per 1 minute)

2. Arterial hypotension + bradycardia (unfavorable prognostic sign mortality increases by 3 times).

\section{Clinical and laboratory symptoms of the post-asphyxia period}

The need for oxygen in such victims is increased by 5 times or more. Disorders of electrolyte and acid-base state of blood:

The blood $\mathrm{pH}$ of victims who are in a comatose state is $7.15 \pm 0.25$ (metabolic or mixed acidosis):

- in the first stage of strangulation asphyxia in most cases respiratory alkalosis is noted;

- in subsequent stages - pronounced respiratory and metabolic acidosis;

- in hypercapnic coma and joining of the syndrome of multiple organ failure - decompensated respiratory and metabolic acidosis.

Sufficiently high $\mathrm{pH}$ and concentrations of serum bicarbonate is a favorable prognostic sign for victims in the post-strangulation period. 
Lactate:

- moderate acute respiratory failure - the norm or increase to $3 \mathrm{mmol} / \mathrm{l}$;

- expressed - an increase up to $4 \mathrm{mmol} / \mathrm{l}$;

- severe - an increase up to $5 \mathrm{mmol} / \mathrm{l}$;

- in hypoxic coma - an increase of more than $7 \mathrm{mmol} / \mathrm{l}$.

In interrupted strangulation asphyxia, transmineralization or "sick cell syndrome" may occur. Potassium is rapidly excreted from the cells (with the development of hyperkalemia), sodium excretion is impaired, it requires energy, which is in short supply due to lack of oxygen. Reducing in the intracellular concentration of ATP damages the normal function of the sodium-potassium pump. Hyperkalemia also depends on the degree of rhabdomyolysis.

Full blood count:

- leukocytosis with a shift of the leukocyte formula to the left;

- increase in the erythrocyte sedimentation rate.

Creatinine phosphokinase (CPK), aspartate aminotransferase, lactate dehydrogenase, glucose and products of its metabolism - lactate (lactic acid) and pyruvate (pyruvic acid), creatinine, creatine phosphate and myoglobin (MG) are the markers that are determined in serum and used to estimate the state of muscle tissue.

Normally, the blood contains an extremely small amount of MG (from 7 to $85 \mathrm{ng} / \mathrm{ml}$ ). When the content of MG in the serum exceeds $250 \mathrm{ng} / \mathrm{ml}$, then myoglobinuria develops with urine staining in brown color.

Normally, the content of CPK is less than $130 \mathrm{IU} / 1$. In rhabdomyolysis, it is released from skeletal muscles. CPK is considered to be a specific marker of these damages, especially when its increases are significant. CPK activity gradually increases in the first 12 hours after muscle damage, reaching its peak on day 3-5 and returning to its initial level within 6-10 days.

Blood chemistry:

- hypoproteinemia, decreased protein ratio below 1.0, levels of a $2-$ and $\gamma$-globulins increase;

- increase in urea and creatinine, decrease in glomerular filtration with an increase in the severity of acute respiratory failure;

- hypoxic cellular damage is characterized by increased transaminases;

- hypoglycemia (levels are variable due to high absorption by the tissues, depend on the degree of asphyxia and tissue perfusion, a decrease 
in the glycogen-synthesizing function of the liver;

- myoglobinemia.

Blood coagulation system and rheology:

- hypercoagulation on the background of a significant increase in the concentration of fibrinogen (as a substance of early response to damage), which can be more than $10 \mathrm{~g} / 1$ in severe acute respiratory failure and coma, the troponin test is positive.

- viscosity of blood and plasma is increased, the functional properties of erythrocytes, which determine the state of blood flow at the level of the microvasculature are disturbed.

Protein- and carbohydrate function of the liver is suppressed.

Prolonged asphyxia is accompanied by growing thyroid insufficiency with a decrease in serum thyroxin level.

Toxic substances formed during rhabdomyolysis have a vasoconstrictor effect on the vessels of Malpighian bodies and damage the epithelium of the convoluted tubules.

Significantly reduced daily diuresis (with a predominance of night over day), edemas, increased level of residual nitrogen in blood. Urine specific gravity tends to decrease, proteinuria is observed. Acid derivatives of myoglobin, cylinders, erythrocytes, and hematin crystals are found in the urine sediment. With the development of acute renal failure, the effects of intoxication intensify.

The degree of these disorders increases depending on the duration of asphyxia, the severity of acute respiratory failure, the degree of muscle damage.

\section{Complications of strangulation asphyxia:}

- Post-hypoxic / post-anoxic encephalopathy.

- Cases of temporary vision loss are known.

- In a number of cases - "tympanic membrane syndrome".

- Chondroperichondritis.

- Damage to the cervical spinal cord is accompanied by appropriate neurological symptoms in the form of tetraplegia or tetraparesis, tetraanesthesia, respiratory disorders (in damage to the fourth cervical segment).

- Respiratory distress syndrome, pulmonary edema, hyperergic aspiration pneumonitis, pneumonia. 
- Bernard-Horner syndrome (ptosis, myosis, enophthalmos).

- Bulbar syndrome in the form of peripheral paralysis of muscles of the tongue, soft palate, vocal cords, epiglottis.

- Myoglobinuric nephrosis.

- Laryngeal deformity, dysphonia, dysphagia, wheezing breathing, hoarseness can be observed

\section{Postasphyctic states in interrupted asphyxia}

1. Arespiratory-comatose stage, characterized by lack of breathing, unconsciousness, lack of reaction of the pupils to light.

2. Decerebration rigidity stage, when the inhibitory effect of the midbrain is still missing. At this stage convulsive movements, mainly of tonic nature develop.

3. Stage of depression of consciousness. Variety of extra-pyramidal symptoms such as tremor, catalepsy, autonomic disorders and the like are observed.

4. Amnesia stage when in full consciousness more or less pronounced retrograde amnesia is determined.

5. The stage of effector effects is often expressed by an acute manic flash, the development of a depressive-melancholic state, and the like.

\section{Treatment}

1. Providing emergency medical care at the prehospital stage.

- Freeing victim's neck from compression. According to the existing algorithms, the victim must be "cut off," that is, using a sharp blade, separate the loop from the carrier part of the ligature. But according to the existing legislation, carrying a knife with you is considered a criminal offense (the object can be regarded as a weapon or not, which should be decided in a lawsuit). For this reason, law-abiding citizens are not able to perform such actions outside the house or outside of work. If the necessary means is available (table or fur knives, pruners, professional cutting tools), then in cutting leading part of the loop, one must support the victim's body to prevent injuries as a result of a fall (in a strong inhibition of muscle tone, injuries can be very severe). To ensure a forensic examination, it is recommended to cut the loop from the side opposite to the closure of the ligature mark (if this does not interfere with the provision of urgent medical care). If the blades are not available, it is necessary to lift the victim's body 
upwards in the cranial direction and be able to free the neck from the loop (in reality, this can be done only by a fairly strong and tall person, or by several rescuers, since the feeling of heaviness of the body with relaxed muscles is much higher than when saving the victim with preserved consciousness). It should be remembered that when trying to just free the neck from the ligature, the victim "folds like a Swiss knife".

- When performing a triad maneuver of P. Safar, do not re-bend the cervical spine, but only perform traction in the cranial direction.

- In circulatory arrest - CPR according to the appropriate protocol.

- Patient's position - lying on a flat surface.

- Mandatory pulse oximetry.

- For strangulated asphyxia victims, in order to reduce the load on the cervical spine, it is necessary to put cervical collar (Schantz neck collar) or apply Kendrick's splint.

- Ensure complete psychological rest and do not allow the patient to move independently.

- Emergency oxygenation:

- Urgent endotracheal intubation on spontaneous breathing (in case of laryngeal edema or fracture of its cartilage, conicotomy or tracheostomy are performed)

- Artificial lung ventilation with $100 \%$ oxygen supply;

- Conducting oxygen therapy is indicated for patients with less than $95 \%$ saturation. Inhalation with humidified oxygen can be performed using a mask or through a nasal catheter with a flow of 6-8 $1 /$ min.

- Anticonvulsant therapy: sodium thiopental - 75-125 mg during 10 minutes, the solution should be administered intravenously slowly at a rate of not more than $1 \mathrm{ml}$ per minute. First, usually $1-2 \mathrm{ml}$ is injected and 20-30 seconds later - the rest; diazepam (sibazon) $0.5 \%$ solution in an amount of $0.2 \mathrm{mg}$ per $1 \mathrm{~kg}$ of body weight intravenously (under the control of breathing and blood pressure).

- Anti-edemic and dehydration therapy with corticosteroids in an amount of $60-90 \mathrm{mg}$ of prednisolone or betamethasone (betaspan) 8-12 mg intravenously, furosemide $20-40$ or torasemide (Thorsid) $10-20 \mathrm{mg}$ intravenously;

- Infusion therapy: in a restrictive mode (colloidal solutions - vital importance, glucose solutions in the acute period are contraindicated). 
- Prevention and treatment of myoglobinuric nephrosis: sodium bicarbonate soulution $4.2 \%-200 \mathrm{ml}$ i / v by drop infusion slowly.

- With the development of arrhythmias, antiarrhythmic therapy is carried out depending on the type of rhythm disturbance.

N.B.! In case of incomplete hanging, successful resuscitation of patients is possible even after 5 minutes from the moment of hanging.

Urgent hospitalization of the patient to a medical institution of secondary medical care:

a). All patients with strangulation asphyxia regardless of gender, age and other factors are subject to urgent hospitalization. The priority task of the emergency medical team is to transport patients to the intensive care center (department).

b). During transportation, it is necessary to ensure monitoring of the patient's condition, monitoring of blood pressure, heart rate, respiratory rate, $\mathrm{ECG}, \mathrm{SaO}_{2}$, treatment and readiness for resuscitation.

c). Transportation is carried out on a stretcher after the patient's condition has stabilized to the emergency medical department of a multidisciplinary hospital, or, not entering the emergency department, directly to the intensive care unit.

d). The territorial health authority must necessarily develop and approve an order or a local protocol (of the appropriate level) that ensures the organization of care for patients with strangulation asphyxia, the interaction between medical institutions that provide emergency, primary and secondary medical care.

2. Treatment at the hospital stage:

- The absolute indications for transferring a patient to artificial lung ventilation are:

- hypoxemic acute respiratory failure $\left(\mathrm{pO}_{2}\right.$ less than $\left.50 \mathrm{~mm} \mathrm{Hg}\right)$;

- hypercapnic acute respiratory failure $\left(\mathrm{pCO}_{2}\right.$ more than $\left.60 \mathrm{~mm} \mathrm{Hg}\right)$;

- critical reduction of reserve respiration (ratio of tidal volume / body weight of the patient - less than $5 \mathrm{ml} / \mathrm{kg}$ );

- respiratory inefficiency (in minute respiratory volume of more than $15 \mathrm{l} / \mathrm{min}$ and normal or moderately elevated $\mathrm{pCO}_{2}$, adequate oxygenation of arterial blood is not achieved).

Artificial ventilation in the intensive care unit, duration from 4:00 to 2-3 days in a mode supporting $\mathrm{PCO}_{2}$ within 28-32 mm Hg. Indications - 
impaired breathing, lack of consciousness, agitation and increased muscle tone, convulsions. Total curarization and mechanical ventilation should be carried out until the complete disappearance of seizures, hypertonia and recovery of consciousness.

- The treatment of this category of patients is carried out differentially depending on the prevailing pathology with the obligatory involvement of a neuropathologist, ENT doctor, traumatologist, neurosurgeon with performing of emergency surgical interventions if necessary.

- After stabilization of patient's state in the conditions of the intensive care unit, patients can be transferred to a specialized unit for the further treatment and rehabilitation.

- Patients with a strangulation trauma as a result of the attempted suicide must be provided with psychiatric care after the completion of the course of treatment.

- Mandatory X-ray examination or (more informative) X-ray computed tomography and MRI of the cervical spine and spinal cord in order to clarify the nature and extent of injuries and exclude extensive intracranial injuries, clarify the prevalence of ischemic brain damage. Such measures are especially indicated for patients with impaired consciousness. CT of the spine is especially important in elderly patients who may have spondylosis of the cervical spine, as well as in patients after strangulation with a jerk.

- Radiography of the chest organs not only allows the diagnosis of chest injuries, but specifies the diagnosis of respiratory distress syndrome as well.

- Prevention and treatment of pneumonia: antibiotic therapy, inhalation, vibration massage of the chest, etc.).

- Anticoagulants and disaggregants - only in the absence of intracranial hemorrhage.

- By indications - surgery on the cervical spine.

- Administration of non-hemoglobin oxygen carriers.

- During intensive therapy, the use of anti-edema drugs, in particular glucocorticoids (30-60 $\mathrm{mg}$ of prednisolone or 8-12 $\mathrm{mg}$ of betamethasone), saluretics (40-60 mg of furosemide or $20 \mathrm{mg}$ of torasemide), $5-10 \mathrm{ml}$ of a $2.4 \%$ solution of theophylline (euphylline) intravenously. 
- In case of convulsive syndrome, $2 \mathrm{ml}$ of a $0.5 \%$ solution of diazepam (sibazone), $10 \mathrm{ml}$ of a $20 \%$ solution of sodium hydroxybutyrate are administered intravenously.

- The use of sodium bicarbonate solution to prevent the development of acute kidney injury syndrome (AKI) is based on the concept of enhancing MG nephrotoxicity under acidic conditions. Therefore, an alkaline environment can reduce the formation of free radicals and the formation of myoglobin cylinders in the kidneys. Hence the likelihood that injection of bicarbonate will make it possible to increase urine $\mathrm{pH}$ higher than 6.5 and prevent development of AKI and metabolic acidosis.

- A $10 \%$ solution of calcium chloride $10-20 \mathrm{ml}$ is also administered intravenously to neutralize the toxic effect of potassium ions on the heart muscle.

- Treatment of post-hypoxic / post-anoxic encephalopathy:

- Saturating dose of $2000 \mathrm{mg}$ of citicoline (lyra, neurocytin), which is administered intravenously at a dilution of $200 \mathrm{ml}$ of electrolyte balanced solution. Maintenance dose is similar to saturating. It is slow drip infusion (up to 20 drops per minute) within 24 hours.

- In the first 14-20 days after the episode of anoxia, choline alfoscerate is administered intravenously in doses of $1000 \mathrm{mg} 2-3$ times a day,

Table 1

\section{Prognosis}

\begin{tabular}{|l|l|l|l|}
\hline \multicolumn{1}{|c|}{ Factors } & The most negative & \multicolumn{1}{|c|}{$\begin{array}{c}\text { Moderately } \\
\text { negative }\end{array}$} & The least negative \\
\hline $\begin{array}{l}\text { Duration of } \\
\text { strangulation }\end{array}$ & $\begin{array}{l}\text { 7-8 minutes and } \\
\text { more }\end{array}$ & From 3 to 7 minutes & To 3 minutes \\
\hline Material of a loop & $\begin{array}{l}\text { Steel string or wire; } \\
\text { loop lubricated with } \\
\text { soap, oil, silicone. }\end{array}$ & $\begin{array}{l}\text { Belt, waist-band, } \\
\text { bed linen, clothing } \\
\text { items. }\end{array}$ & $\begin{array}{l}\text { Soft atraumatic } \\
\text { materials (in sexual } \\
\text { perversions). }\end{array}$ \\
\hline $\begin{array}{l}\text { Movability } \\
\text { of a loop }\end{array}$ & Loop is movable. & $\begin{array}{l}\text { Loop is partially } \\
\text { movable. }\end{array}$ & Loop is immovable. \\
\hline $\begin{array}{l}\text { Type of closure of } \\
\text { ligature mark (node } \\
\text { position) }\end{array}$ & Posterior & Lateral & Anterior \\
\hline $\begin{array}{l}\text { Localization of } \\
\text { ligature mark }\end{array}$ & Above the larynx & $\begin{array}{l}\text { At the medial level } \\
\text { of the larynx }\end{array}$ & Below the larynx \\
\hline By mechanism & With a jerk & Quickly & Slowly \\
\hline
\end{tabular}


followed by a switch to oral administration (400 mg 3 times a day). Duration of treatment is 5-6 months.

- Daily infusion of amantadine sulfate (PK-Merz) $200 \mathrm{mg} 2$ times a day for 5 days (the rate of administration of one vial is at least 180 minutes) is recommended. Subsequently (if possible) it is recommended to switch to a tableted dosage form (100 mg 3-4 times a day for up to 4 weeks).

\section{Conclusions}

- Proper care of children, persons with disabilities and mental disorders (including the elimination of the technical possibility of hanging).

- Compliance with safety precautions when working with rotating mechanisms; riding in cabriolets, motorcycles, mopeds, etc.

- Prevention and treatment of alcoholism, drug addiction (drug dependency treatment).

- Prevention and treatment of suicidal intentions and sexual perversions (psychological and psychiatric care).

\section{References:}

1. Polutova N.V., Chesnokova N.P., Ponukalina E.V., Bizenkova M.N. (2017). Lektsiya 12 Asfiksiya: stadii narusheniya vneshnego dykhaniya, mekhanizmy razvitiya [Lecture 12 Asphyxia: Stages of disorder of external respiration, developmental mechanisms] Scientific Review. Medical sciences, no. 2, pp. 57-60.

2. Skidanov A.Gh., Leontyeva F.S., Morozenko D.V., Piontkovsky V.K., Radchenko V.O. (2016). Biokhimichni markery dlja ocinjuvannja stanu m'jaziv za umov degheneratyvnykh zakhvorjuvanj khrebta (oghljad literatury) [Biochemical markers for muscles condition assessment in degenerative spinal deceases (literature review)]. Orthopaedics, Traumatology and Prosthetics, no. 4, pp. 119-123.

3. Kryakunov N.K. (2005). Strangulyatsionnaya asfiksiya [Strangulation asphyxia] Emergency Medical Care, vol. 6, no. 2, pp. 63-68.

4. Viter V.I., Vavilov A.Yu., Kungurova V.V., Babushkina K.A. (2016). Mekhaniches-kaya asfiksiya: sudebno-meditsinskaya diagnostika $i$ otsenka: uchebnoe posobie [Mechanical asphyxia: forensic diagnosis and assessment: Teaching aid]. Izhevsk. (in Russian)

5. Yekhalov V.V., Volkov O.O., Dzyak L.A., Zozulya O.O., Kligunenko O.M., Lyashchenko O.V., Sedinkin V.A., Stanin D.M. (2019). Mekhanicheskaya asfiksiya [Mechanical asphyxia]. Dnipro: LIRA. (in Russian)

6. Nikonov V.V., Savitskaya I.B., Nud'ga A.N., Kinoshenko E.I., Kovaleva E.A., Pavlenko A.Yu. (2008). Postgipoksicheskaya entsefalopatiya: 
vozmozhnosti korrektsii [Posthypoxic encephalopathy: correction possibilities] Emergency Medicine, no. 4 (17), pp. 65-71.

7. Semenov G.G. (2005). Diagnosticheskoe znacheniy priznakov narusheniya gemodinamiki pri nekotorykh vidakh mekhanicheskoy asfiksii [Diagnostic values of signs of hemodynamic disturbances in certain types of mechanical asphyxia]. (dis. Cand. Med. Sciences). Moscow.

8. Bordakov V.N., Alekseev S.A., Chumanevich O.A., Patsaj D.I., Bordakov P.V. (2013). Sindrom dlitel'nogo sdavleniya [Crush-syndrome] Military Medicine, no. 1, pp. 26-32.

9. Teplova N.N. (2016). Rabdomioliz v klinicheskoy praktike (obzor literatury) [Rabdomyolisis in clinical practice (review)]. Medical Newsletter of Vyatka, no. 4(52), pp. 37-45.

10. Klyhunenko O.M., Dziak L.A., Yekhalov V.V. (2011). Sumizhni spetsialnosti dlia khirurha [Related specialties for a surgeon]. H. V. Dziak (eds), Khirurhiia [Surgery] (Vol. 3, bk. 3). Dnipropetrovsk: Dnipro-VAL. (in Ukrainian)

11. Gandhi R., Taneja N., Mazumder P. (2011). Near hanging: Early intervention can save lives. Indian J Anaesth., vol. 55(4), pp. 388-391.

12. Jawaid M.T., Amalnath S.D., Subrahmanyam D.K.S. (2017). Neurological Outcomes Following Suicidal Hanging: A Prospective Study of 101 Patients. Annals Indian Academy of Neurology, no. 20(2), pp. 106-108.

13. Sauvageau A., Boghossian E. (2010). Classification of Asphyxia: The Need for Standardization. Journal of Forensic Sciences, no. 55(5), pp. 1259-1267.

14. Sutcliffe W.J.C., Saayman A.G. (2018). Hanging and asphyxia: Interventions, patient outcomes and resource utilisation in a UK tertiary intensive care unit Journal of the Intensive Care Society, no. 19(3), pp. 201-208.

15. Yekhalov V., Khobotova N. (2019). Obturative asphyxia. Development of modern science: the experience of European countries and prospects for Ukraine. 3rd ed. Riga, Latvia: Baltija Publishing, pp. 293-307. 